\title{
Liquid Crystal Templating of Nanomaterials with Nature's Toolbox
}

\author{
Georg R. Meseck ${ }^{\dagger}$ Andrea S. Terpstra ${ }^{\dagger}$ and Mark J. MacLachlan* \\ Department of Chemistry, University of British Columbia, 2036 Main Mall, Vancouver, BC, V6T 1Z1, \\ Canada
}

*Corresponding author:

Email: mmaclach@chem.ubc.ca

${ }^{\dagger}$ Authors contributed equally

Keywords: liquid crystals, templating, cellulose nanocrystals, chitin, viruses, biopolymers

\begin{abstract}
Naturally occurring biomolecules are sustainable and green precursors for the development of new materials. Within this family of natural materials, cellulose nanocrystals (CNCs) have emerged as one of the most promising materials because of their outstanding physico-chemical properties and the possibility to produce them in large quantities. One key trait of CNCs is their ability to self-assemble into a chiral nematic liquid crystalline phase. In this review, we discuss how templating can be used to transfer the three-dimensional structure of liquid crystalline phases onto solid materials. This is followed by examples that illustrate the fascinating properties and potential applications that arise from the resulting nanostructured materials such as sensing and catalysis. We then summarize efforts to use the liquid crystalline phase of a selection of other biopolymers for templating. While nanocrystalline chitin, having very similar properties to $\mathrm{CNCs}$, has been successfully employed to make a variety of new materials, efforts to template liquid crystal phases of other biomolecules have been met with limited success. However, we discuss virus nanoparticles and collagen as examples to highlight further possibilities for materials research.
\end{abstract}

(C) 2016. This manuscript version is made available under the Elsevier user license http://www.elsevier.com/open-access/userlicense/1.0/ 


\section{Introduction}

Nanoscience and nanotechnology have the potential to revolutionize health care, transportation, food, and other massive areas of our lives [1]. With features that are only 1-100 nm in length - a mere fraction of the width of a hair - nanostructures and nanomaterials are being incorporated into sensors [2,3], solar cells[4,5], displays[6,7], batteries [8-10], and many other technologies. Much of the recent developments in the field have been driven by the development of instrumentation that allows for rapid visualization and manipulation of features on this length scale, allowing one to rapidly screen and evaluate new synthetic materials. Indeed, the synthesis of nanostructured materials is of paramount importance for developing new nanotechnologies. Chemists have many methods at their disposal to control the composition, structure, surface chemistry, and hierarchical organization of nanomaterials. Top-down approaches such as ball milling and etching allow one to transform a bulk material into a nanostructured form. On the other hand, bottom-up approaches, such as self-assembly, are emerging as powerful means to develop new structures with controlled architectures and narrow size distributions [11].

Porous materials with nanometer-scale holes are attractive for separation membranes [12], gas storage $[13,14]$, catalyst supports $[12,15,16]$, and other applications. There have been tremendous efforts expended to develop porous materials with control over pore sizes, shape, and arrangement. In the case of zeolites, it is a cation that functions as a template for the formation of a porous, ion-exchangeable aluminosilicate framework. By changing the size of the cationic template, it is possible to control the size of the channels in the structure. Small molecular templates are an excellent route to porous materials with pores up to $\sim 2 \mathrm{~nm}$ in diameter, but accessing materials with larger pores requires a supramolecular approach where the template is something larger than a molecule or small ion.

In 1992, Kresge et al. reported a breakthrough in the field of materials chemistry, now known as liquid crystal templating $[17,18]$. By condensing tetraethoxysilane (TEOS) in the presence of a surfactant, they obtained amorphous silica with a hexagonal honeycomb lattice of holes filled with surfactant. Upon removal of the surfactant, the resulting mesoporous materials (called MCM-41) contained a periodic arrangement of pores with diameters that could be adjusted from 1.5 to ca. $10 \mathrm{~nm}$. The materials are 
thought to be formed by templating, where silica is condensed in the aqueous regions around a preassembled liquid crystalline phase of the surfactant. (Note that this mechanism is widely accepted but not fully supported in the case of MCM-41) [19]. Using surfactants with chiral head groups gives mesoporous materials with twisting channel structures [20].

Since the discovery of MCM-41, a variety of liquid crystalline templates have been employed to make porous materials. Diverse molecular and polymeric, ionic and neutral substances have been used as templates. Templating has been performed in water, alcohol, formamide, ammonia, and other solvents. Block copolymers (e.g. Pluronics), in particular, can be used to template porous materials with much larger holes than molecular surfactants $[21,22]$. As well, the symmetry of the pores and their connectivity can be controlled by choosing appropriate templates.

Despite the significant advances in templating with synthetic molecular and polymeric substances, these templates are very simple compared with the vast, complex templates available in nature, such as proteins, carbohydrates, bone, and DNA. Nature's templates have complexity both at the molecular scale and in their supramolecular organization [23], all of which may be imprintable in a nanostructured material. Conceptually, the materials and structures found in nature offer a rich and sophisticated toolbox of templates that can be used to make complex materials with hierarchical structures. As well, these materials are biodegradable and often renewable. One recent example where natural materials were directly employed as a template is the deposition of silsesquioxanes on the chitin skeleton of a marine sponge [24].

Many natural substances, such as DNA, cellulose, and silk are known to form liquid crystals in water or other solvents [25-29**]. In these structures, the biomolecules are organized into chiral hierarchical assemblies that span multiple length scales. These present exciting opportunities for templating, and materials chemists are now widely exploring these substances as templates [30]. Here, we take you on a journey through the various classes of liquid crystalline biomolecules that have been applied as templates to construct porous materials. Although this review is not comprehensive, it is our goal to 
capture the excitement in the area with a focus on cellulose nanocrystals (CNCs) and nanocrystalline chitin (NCh).

\section{CNCs}

\subsection{Properties}

Cellulose is one of the most abundant and versatile biopolymers found in nature. It is commonly isolated from the cell walls of plants and algae but can also be isolated from certain species of bacteria, fungi and marine animals [31,32]. Cellulosic materials are widely used in the pulp and paper industry but are also being investigated as additives in composite materials, in medical applications and as a templaties [33-35**]. Its unique combination of mechanical support, flexibility, abundance and biocompatibility presents promising applications for cellulose in the field of materials chemistry.

Naturally derived cellulose microfibers are isolated from the cellular matrix through either alkali and oxidative extraction treatment, usually $2-4 \% \mathrm{NaOH}$ at elevated temperatures, or acidic treatments followed by subsequent bleaching to remove soluble polysaccharides and residual phenolic molecules [36]. These isolated cellulose microfibers are composed of a linear polymer of D-glucose units linked through 1,4-glycosidic bonds. In plants, the microfibers contain highly crystalline regions of exclusively cellulose I, a parallel arrangement of cellulose chains held together by hydrogen bonding, that are separated by amorphous regions [37]. Cellulose microfibers can be 2-20 $\mathrm{nm}$ in diameter and tens of microns long [36].

In 1951, Rånby developed a method to isolate the crystalline regions of cellulose microfibers through acid hydrolysis [38]. Exposing the cellulose microfibers to mild acidic conditions selectively degrades the amorphous regions in the microfibers, thereby yielding rod-shaped CNCs (Fig. 1). Isolated $\mathrm{CNC}$ rods can vary between 50 to $2000 \mathrm{~nm}$ in length depending on the biological source from which they

are extracted [32]. For example, $\mathrm{CNC}$ rods from wood and cotton have diameters of 5 to $10 \mathrm{~nm}$ and are 100 to $200 \mathrm{~nm}$ long, whereas CNC extracted from algae and tunicates can have lengths of 1000 to 2000 $\mathrm{nm}$. Extraction of CNCs using sulfuric acid is the most investigated preparative method because hydroxyl 
groups on the $\mathrm{CNC}$ rods are partially converted into sulfate esters during hydrolysis. The introduction of these negative sulfate surface groups helps stabilize aqueous dispersions of CNCs through electrostatic repulsion.

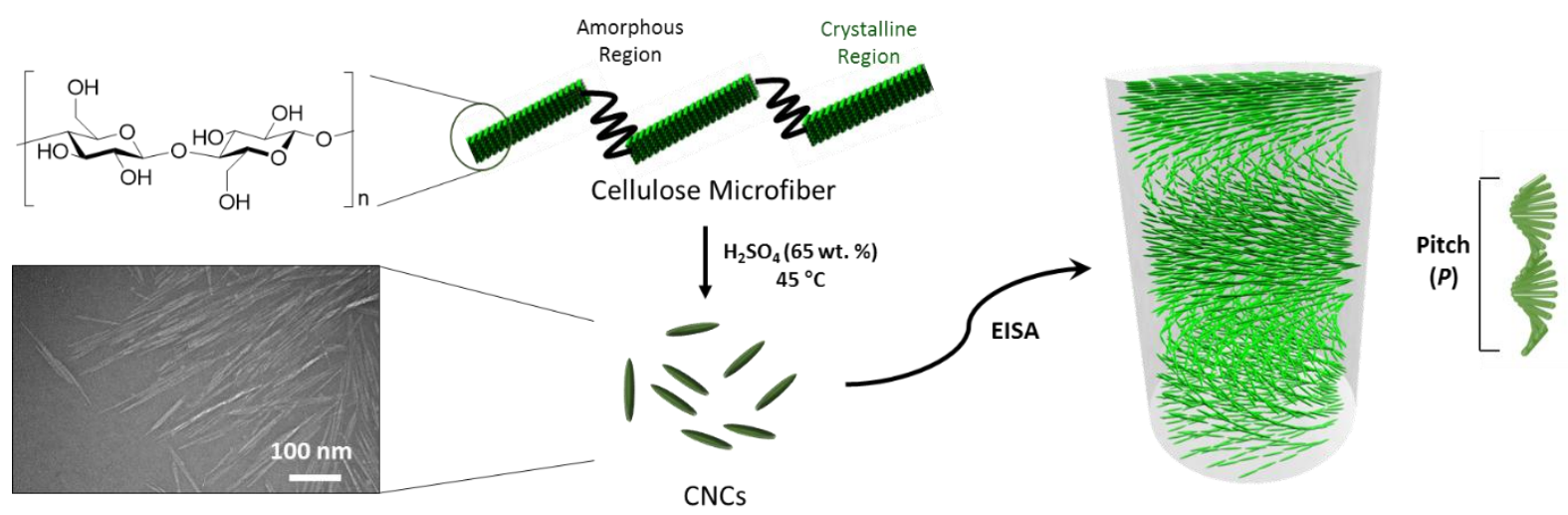

Fig. 1. Schematic for the extraction of CNCs from cellulose microfibers by acid hydrolysis. Bottom left: negatively stained transmission electron micrograph of CNCs.

The lyotropic liquid crystalline phase of a colloidal CNC suspension was first reported in 1959 by Marchessault et al. [39]; the chiral nematic phase, however, was not identified until 1992 by Gray and coworkers [29]. Analyzing CNCs extracted from wood microfibers using sulfuric acid, Gray and coworkers demonstrated that CNCs form a chiral nematic liquid crystal (LC) above a critical concentration (Fig. 1). The CNC rods act as LC mesogens and align along their long molecular axis. In the simplest case, this alignment would lead to a nematic phase with long-range orientational order but no positional ordering. Chirality can be introduced into the nematic system causing an intrinsic helical twist perpendicular to the long axis of the mesogens [40]. In the case of CNCs, only left-handed (LH) chiral nematic structures have been observed.

CNC films obtained through evaporation-induced self-assembly (EISA) retain the chiral nematic structure of the CNC rods [41]. The CNC films contain three different levels of chirality: (1) chirality at the molecular level attributed to asymmetric carbon atoms in the D-glucose subunits; (2) chirality of the twisted morphology of the individual CNC rods; and (3) chiral nematic ordering of the LC. This longrange chiral nematic ordering imparts photonic properties on the $\mathrm{CNC}$ films. Photonic crystals are 
materials that have periodic layers with different refractive indices, leading them to selectively diffract light of a wavelength on the order of the layer spacing. The relationship between the wavelength reflected $\left(\lambda_{\max }\right)$ by the chiral nematic structure, refractive index $\left(\mathrm{n}_{\text {avg }}\right)$ and helical pitch $(\mathrm{P})$ can be described by the following equation: $\lambda_{\max }=\mathrm{n}_{\text {avg }} P \sin \theta$ (Fig. 1) [42]. Only light with a circular polarization that matches the handedness of the helical structure is reflected; thus, CNC films reflect only LH circularly polarized light since they have LH organization. As the helical pitch of the CNC films is on the order of microns, the reflected light can range from the ultra-violet through visible and to near-IR wavelengths.

\subsection{CNC/Silica Materials}

The first example of CNC templating was reported in 2003 [43]. Dujardin et al. showed that an aqueous CNC suspension could be mixed with a solution of prehydrolyzed tetramethoxysilane (TMOS). Upon EISA, the CNC rods acted like a LC template and produced birefringent silica composite materials. However, no long-range chiral nematic ordering was observed in their materials.

In 2010, the MacLachlan group reported the synthesis of free-standing chiral nematic mesoporous silica (CNMS) films with long-range chiral nematic ordering imparted by CNCs (Fig. 2a) [35]. This was achieved by hydrolysis and condensation of the alkoxysilane precursors TMOS and TEOS in a 3 wt $\%$ aqueous solution of CNCs, followed by EISA. The resulting CNC/silica composite films displayed strong iridescent colors and intense signals with positive ellipticity measured by circular dichroism (CD) spectroscopy. This left-handed CD signal matched the wavelength of reflected light measured by UV-Vis spectroscopy, indicating that the light reflected from the films was exclusively left-handed circularly polarized. Shopsowitz et al. were able to control the helical pitch of the material by tuning the amount of silane precursor added when synthesizing the composite $\mathrm{CNC} /$ silica materials. Increasing the silica-to$\mathrm{CNC}$ ratio resulted in an increasing helical pitch and allowed tuning of the reflected wavelength of light across the whole visible spectrum from ultraviolet to infrared.

The CNCs were removed from the composite materials by calcination at $540{ }^{\circ} \mathrm{C}$ under air yielding free-standing mesoporous silica films (Fig. 2c) [35]. The resulting silica films showed intense iridescent 
colors (exclusively LH circularly polarized) that were blue-shifted from the respective composite films. Mesoporosity of the films was confirmed by nitrogen adsorption measurements showing high surface areas ranging from $300-800 \mathrm{~m}^{2} \mathrm{~g}^{-1}$ and pore volumes of 0.25 to $0.60 \mathrm{~cm}^{3} \mathrm{~g}^{-1}$. The Barrett-JoynerHalenda $(\mathrm{BJH})$ pore size distributions of 3 to $5 \mathrm{~nm}$ were similar but slightly smaller in dimension to the $\mathrm{CNC}$ rods owing to contraction of the silica during calcination. Retention of the chiral nematic structure imparted by the CNC template was confirmed by scanning electron microscopy (SEM) (Fig. 2b). The long-range periodic structure is apparent throughout the thickness of the films while the mesopores twist in a counter clockwise direction, consistent with the LH chiral nematic structure of CNCs. Additionally, Kelly et al. found that adding glucose to the $\mathrm{CNC} /$ silica solution prior to EISA changed the sol-gel curing kinetics [44] and reduced cracking of the composite films without affecting self-assembly of the CNC rods [45]. Large, crack free homogeneous CNMS films were created after calcination with diameters reaching up to $15 \mathrm{~cm}$.

In 2012, the procedure to synthesize CNMS films was extended to chiral nematic mesoporous organosilica (CNMO) films (Fig. 2c) [46]. Bis(trimethoxysilyl)ethane (BTMSE) and 1,4bis(triethoxysilyl)benzene (BTESB) were used as silane precursors to produce silica films with ethylene or phenylene bridging groups in the backbone of the matrix [46,47]. An alternative method to remove the $\mathrm{CNC}$ template using $6 \mathrm{M}$ sulfuric acid prevented the degradation of the organic spacers as confirmed by solid-state ${ }^{13} \mathrm{C}$ and ${ }^{29} \mathrm{Si}$ cross-polarization magic-angle-spinning NMR spectroscopy. Nitrogen adsorption measurements of CNMO films displayed high surface areas of 400 to $740 \mathrm{~m}^{2} \mathrm{~g}^{-1}$ and pore volumes of $0.6-$ $1.0 \mathrm{~cm}^{3} \mathrm{~g}^{-1}$. Pore diameters of $7-9 \mathrm{~nm}$ in the CNMO films match the average diameters of CNCs as measured by electron microscopy. The chiral nematic organization in the organosilica materials was observed with SEM and helium ion microscopy (HIM) [47]. HIM is a technique that allows insulating materials to be imaged directly without the addition of a conductive coating. At high magnification, the HIM images show that removal of the $\mathrm{CNC}$ rods creates a woven porous structure of individual mesopores that twist along the chiral nematic axis oriented vertically in the plane of the image (Fig. 2d). The average pore diameter measured by HIM $(8.4 \pm 2.1 \mathrm{~nm})$ was in good agreement with the pore 
diameters measured by nitrogen adsorption. By incorporating organic functionality into the pore structure, the CNMO films had improved mechanical properties in terms of their flexibility and tensile strength compared to the brittle CNMS films.

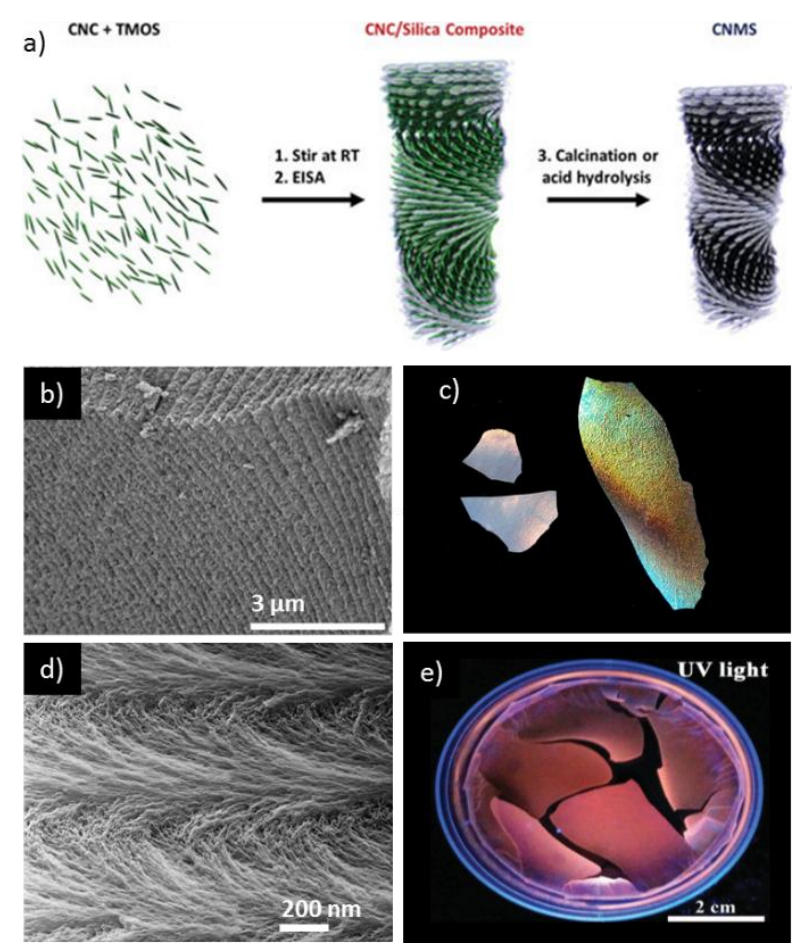

Fig. 2. Chiral nematic CNC-derived materials. (a) Scheme for the synthesis of CNMS from CNCs. Reproduced from [48] with permission from John Wiley and Sons. (b) SEM of CNMS films. Reprinted by permission from Macmillan Publishers Ltd: Nature [35], copyright 2010. (c) CNMS (left) and CNMO (right) films. (d) HIM of CNMO films. Reproduced from [47] with permission from the Royal Society of Chemistry. (e) CdS QD/silica composite material. Reproduced from [49] with permission from John Wiley and Sons.

The CNMO and CNMS films have a wide range of promising applications including sensors, chiral catalyst, chiral separation and as chiral support materials. One important property of CNMS and CNMO films is the birefringence resulting from the porous nanostructure. Incorporating guest molecules into the porous network was found to alter the optical properties of the films. Shopsowitz et al. demonstrated this by introducing different solvents into the porous network of the CNMS films [35]. If the refractive index between the solvent in the pores and silica were closely matched (e.g. $\mathrm{n}=1.33$ for $\mathrm{H}_{2} \mathrm{O} ; \mathrm{n}$ $=1.46$ for $\mathrm{SiO}_{2}$ ) the reflectance color is quenched and the films appear translucent. This relationship between the refractive indexes of the silica material and guest molecules inside the pores allows these 
materials to be used as sensors. Taking advantage of the CD signal of the films, it was possible to measure the refractive index of aqueous sucrose solutions using this method, allowing the determination of sucrose concentrations in water [48]. Thermotropic LCs, 4-cyano-4'-octylbiphenyl (8CB) and phloroglucinol derivatives, were incorporated into the chiral nematic mesoporous materials to control the photonic properties of the films through external stimuli. Changes in temperature altered the alignment of these molecules and caused the refractive index and, thus, the reflected wavelength to change [50,51]. The response of the optical properties to guest molecules offers a new route to produce tunable optical filters or temperature sensors based on CNC LC templated materials.

CNMS materials can also be used for enantioselective separation, chiral supports for catalysis, and as solid supports for metal nanoparticles (NPs) and quantum dots (QDs). In 2014, Zhang et al. developed a CNMS-coated column for gas chromatography separations to test CNMS for the separation of a variety of achiral and chiral molecules [52]. The CNMS-coated capillary column had good selectivity for the separation of linear alkanes, aromatic hydrocarbons, polycyclic aromatic hydrocarbons and isomers, and reasonable enantioselectivity for chiral compounds like 2-amino-1-butanol, isoleucine, and serine. Qi et al. and Kelly et al. synthesized CNMS films doped with silver, gold or platinum nanoparticles (NPs) to produce functional hybrid materials where the supramolecular arrangement of the particles is controlled by the CNC LC template [53,54]. These NP/CNMS composites were formed by either introducing the NP precursors to the CNC and silica solution prior to EISA (co-assembly) or after the CNMS was synthesized (post-synthetic modification). Nguyen et al. reported the synthesis of CNMS films doped with CdS QDs [49]. These QD/CNMS composite materials were formed by co-assembling pre-assembled CdS QDs with a CNC and silica solution. The resulting composite material showed the iridescence of the CNMS host as well as luminescence of the QDs (Fig. 2e). Fluorescence measurements showed a gradual quenching in the emission intensity of the QD/CNMS films when they were exposed to 2,4,6-trinitotoluene (TNT) vapors, illustrating that these composites have significant promise as solid chiral supports for sensing applications.

Shin and Exarhos were the first to prepare porous titania films templated with CNCs [55]. Although they obtained free-standing films, the long-range chiral structure of the CNC rods was not 
retained. Ivanova et al. also reported the synthesis of porous titania films templated directly from CNCs, but no long-range helical properties were measured [56]. In 2012, MacLachlan and coworkers devised a procedure to obtain chiral nematic titania films through hard templating with CNMS [57]. Hard templating using CNMS allows transfer of the chiral nematic structure from the CNC LC template to be imparted into materials that are less compatible with aqueous CNC suspensions. Titania/silica composite materials were synthesized by repeatedly loading $\mathrm{TiCl}_{4}$ into the pores of CNMS films, which were then annealed, calcined and exposed to sodium hydroxide to remove the silica support. The resulting chiral nematic mesoporous titania films reflected LH circularly polarized light and exhibited a long-range chiral nematic structure when analyzed by SEM. PXRD and nitrogen adsorption analysis showed that the films were composed of anatase with surface areas of $149-234 \mathrm{~m}^{2} \mathrm{~g}^{-1}$. A similar hard templating procedure was employed for the synthesis of chiral zirconia films and zinc Prussian blue/silica materials [58,59]. The chiral nematic mesoporous zirconia films were analyzed by SEM, nitrogen adsorption and PXRD measurements, revealing a tetragonal $\mathrm{ZrO}_{2}$ structure with surface areas of $140-182 \mathrm{~m}^{2} \mathrm{~g}^{-1}$ and retention of the chiral nematic structure. The zinc Prussian Blue analog composite films also retained the chiral nematic ordering, but removal of the silica template resulted in disordered porous films.

Nguyen et al. reported a novel method to produce chiral alumina films through hard templating with CNMS films [60]. CNMS films carefully wrapped in aluminium foil were heated to $800{ }^{\circ} \mathrm{C}$ for $20 \mathrm{~h}$ to accelerate the aluminothermic reduction of silica and produce alumina/silicon composite materials, which were subsequently treated with sodium hydroxide to selectively etch away the silicon, yielding freestanding porous chiral alumina films. PXRD and EDX analysis revealed that the films are composed of pure $\mathrm{Al}_{2} \mathrm{O}_{3}$ in the crystalline corundum phase. SEM and nitrogen adsorption measurements showed that the chiral nematic structure imparted by the CNMS was retained and the materials have surface areas of $180 \mathrm{~m}^{2} \mathrm{~g}^{-1}$ with pore sizes ranging from $2.5-5.5 \mathrm{~nm}$. Additionally, the alumina/silicon composite could be treated with $0.1 \mathrm{M} \mathrm{HCl}$ to remove $\beta$-alumina and afford chiral nematic porous corundum/silicon films. 


\subsection{CNC/Organic Materials}

Research on the addition of CNCs to organic polymer materials has been motivated predominantly by improving the mechanical properties of the polymer. Here, we highlight the use of CNCs as a LC template to synthesize novel chiral nematic polymeric materials.

Hydrogels templated with CNCs were first reported by Tatsumi et al. in 2012 [61]. One of the composite materials they prepared was an anisotropic poly(2-hydroxyethylmethacrylate)/CNC film that showed a fingerprint texture under POM and long-range chiral nematic ordering by SEM. In 2013, Kelly et al. synthesized a series of composite hydrogel/CNC materials from 2-hydroxyethylmethacrylate, $N$ isopropylacrylamide, acrylic acid, acrylamide, polyethyleneglycol dimethacrylate, and polyethyleneglycol methacrylate $[62 *]$. Each monomer was mixed into an aqueous solution of CNCs that contained a crosslinker and a photoinitiator. Once fingerprint textures could be seen under POM, films were irradiated with UV light to initiate polymerization. The resulting hydrogel materials had an observable reflectance peak in the visible range and were tested for sensing applications. The composite materials undergo reversible swelling in response to a large range of stimuli including changes in $\mathrm{pH}$ and solvent polarities. As the hydrogels swell, the helical pitch of the chiral nematic ordered CNCs expands, resulting in a red-shift of the reflected wavelength. Additionally, the degree of polymerization of the hydrogel could be controlled using a photomask during irradiation with UV light. Less cross-linked regions of the hydrogels that were less exposed to UV light swell more, creating patterns observable only after immersing the hydrogel in water (Fig. 3a). 

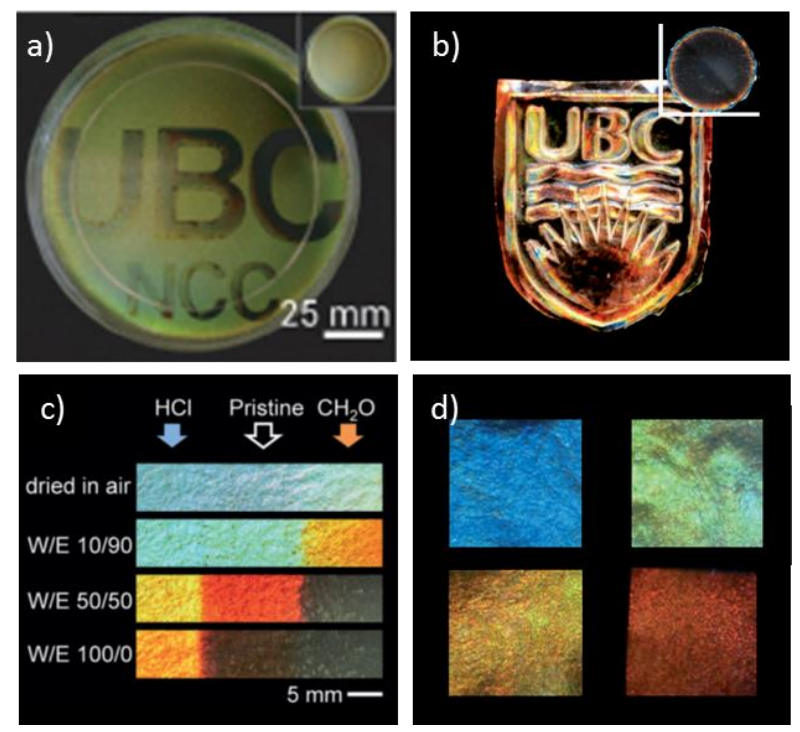

Fig. 3. Organic CNC composite materials. (a) CNC/polymer hydrogel swelling in water. Reproduced from [62] with permission from John Wiley and Sons. (b) MUF films response to compression. Reprinted with permission from [63], copyright 2013 American Chemical Society. (c) PF films swelling in water. Reproduced from [64] with permission from John Wiley and Sons. (d) Mesoporous cellulose films soaked in ethanol/water at different ratios. Reproduced and adapted from [65] with permission from John Wiley and Sons.

In 2013, Khan et al. reported the synthesis of resin/CNC composite materials by mixing watersoluble phenol-formaldehyde (PF) or melamine-urea-formaldehyde (MUF) precursors with CNCs, followed by EISA $[63,64,66]$. The composite materials were thermally cured to enhance cross-linking of the organic polymer followed by selective removal of the CNCs using sodium hydroxide. Thermogravimetric analysis (TGA), solid-state NMR spectroscopy and nitrogen adsorption analysis revealed $85-90 \%$ of the CNCs were removed from the PF matrix and the resulting mesoporous chiral nematic PF resins had surface areas, pore diameters and pore volumes of $310-365 \mathrm{~m}^{2} \mathrm{~g}^{-1}, 7 \mathrm{~nm}$, and $0.5-$ $0.7 \mathrm{~cm}^{3} \mathrm{~g}^{-1}$, respectively, after supercritical $\mathrm{CO}_{2}$ drying. SEM images showed retention of the chiral nematic structure imparted by the CNCs within the resin materials. The mesoporous resins reflect light in the visible range and were tested for sensing applications. The MUF/CNC composites are highly compressible and, therefore, the pitch of the chiral nematic ordering can be tuned by compressing the materials. By applying pressure onto the MUF polymer (40 wt \%) film that reflected red light, a reversible blue-shift in the reflected wavelength was observed by UV/Vis and CD spectroscopy. Interestingly, curing the MUF/CNC films at $100{ }^{\circ} \mathrm{C}$ after compression caused the films to permanently hold the new helical 
pitch. Thus, by first imprinting a raised surface onto the film then curing, it was possible to make plastic samples with a photonic imprint (Fig. 3b).

In the mesoporous PF resin films, the density of hydroxymethyl groups affected the degree of swelling of the films. PF films treated with acid showed enhanced cross-linking and less surface methylol groups (rendering them more hydrophobic) while PF films treated with formaldehyde became more hydrophilic. By applying either acid or formaldehyde to selected regions of the PF films, Khan et al. could alter the swelling behavior of the film and create patterns that were observable only after the addition of water (Fig. 3c) [64*]. These patterned photonic resin films have potential applications in displays, security tags and microfluidic devices. Further research by Cheung et al. demonstrated that neutralized CNC suspensions could be readily dispersed in polar aprotic organic solvents, such as DMF, and be used to template $\mathrm{CNC} /$ polymer composite materials that were previously not accessible [67].

Chiral nematic mesoporous materials made entirely of cellulose nanocrystals, also referred to as photonic paper, were developed by Giese et al. and Schlesinger et al. using two distinct routes. CNCs were co-condensed with either urea formaldehyde (UF) or TMOS and allowed to undergo EISA forming $\mathrm{CNC/UF}$ or $\mathrm{CNC} /$ silica composites, respectively $\left[65^{*}, 68,69\right]$. The UF polymer or silica matrix was removed through an alkaline treatment, resulting in a novel mesoporous cellulose film (Fig. 3d). SEM and nitrogen adsorption measurements revealed long-range chiral nematic ordering in the mesoporous cellulose films with BET surface areas of $250-310 \mathrm{~m}^{2} \mathrm{~g}^{-1}$, pore volumes of $0.5-0.7 \mathrm{~cm}^{3} \mathrm{~g}^{-1}$ and pore diameters of 6-8 nm. Similar to the CNMS films, the helical pitch of the cellulose films can be controlled by varying the ratio of the precursors used during synthesis, and also the type of base treatment used and whether a super critical drying step is performed. The absence of sulfate ester groups on the CNC rods in the cellulose films greatly improves the stability of the films in polar solvents. Interestingly, the mesoporous cellulose materials swell more rapidly in response to water than the $\mathrm{CNC} /$ hydrogels materials with the reflected wavelength of the films shifting up to $400 \mathrm{~nm}$ in $10 \mathrm{~s}$.

The synthesis of pure chiral nematic mesoporous carbon (CNMC) materials was developed by Shopsowitz et al. [70]. First, CNC/silica composite films were synthesized by EISA and then pyrolyzed 
under an inert nitrogen atmosphere at $900{ }^{\circ} \mathrm{C}$ to form carbon/silica composites. TGA showed that this process converted the CNCs into carbon with a yield of $30 \mathrm{wt} \%$. CNMC films were obtained by removal of silica with sodium hydroxide, and SEM and TEM analysis confirmed retention of the chiral nematic structure in the carbon. The porosity of the films was controlled by the amount of silica precursor used in the original $\mathrm{CNC} /$ silica composites and ranged from microporous to mesoporous with surface areas of 570 - $1460 \mathrm{~m}^{2} \mathrm{~g}^{-1}$ and pore volumes of $0.3-1.2 \mathrm{~cm}^{3} \mathrm{~g}^{-1}$. Since mesoporous carbon materials have been shown to have applications in electrochemical capacitors and field-effect transistors, [71,72] the conductivity of the CNMC films was tested. Variable-temperature conductivity measurements demonstrated that CNMC films have semiconducting properties between $20-180{ }^{\circ} \mathrm{C}$. Galvanostatic/discharge profile showed a symmetrical triangle shape of near-ideal capacitor behavior with a current load of $230 \mathrm{~mA} \mathrm{~g}^{-1}$.

\subsection{Hydroxypropylcellulose and Ethylcellulose}

Other cellulose derivatives, such as hydroxypropylcellulose (HPC) and ethylcellulose (EC), can also form LC phases. These derivatives have substantially higher critical concentrations (40 - $70 \mathrm{wt} \%)$ than CNCs that often results in slow self-assembly, high viscosity of the solutions and low solubility of the composite precursors.

The lyotropic LC phase of HPC was first reported 1976 [26]. Since then, HPC has been used in an array of organic templating approaches, yielding composite materials such as HPC/polyacrylic acid [73, 74]. Although the chiral nematic structure of the composite materials are observable by POM and SEM, little research into removing the HPC template has been done. In 2006, Goto and Akagi synthesized a poly(3,4-ethylenedioxythiophene) (PEDOT) / HPC composite material by electrochemical polymerization of 3,4-ethylenedioxythiophene with an aqueous solution of $65 \mathrm{wt} \%$ HPC. Circular differential interference contrast microscopy of the composite revealed an ordered structure that could be attributed to the LC texture of HPC. Additionally, the PEDOT/HPC composite films showed electrochromism through a repeating change in the CD spectra during the electrochemical redox process [75]. In 2003, Thomas and Antonietti generated porous silica through condensation of TMOS and HPC in an aqueous hydrochloric 
acid solution [76]. The mixture was sealed in a rubber tube and stored, allowing the mixture to mature and organize into a lyotropic LC phase. The solvent was removed by vacuum, then the HPC/silica composite was calcined at $550{ }^{\circ} \mathrm{C}$ to form mesoporous silica films. Although the chiral nematic structure of the HPC was observable in the composite films by SEM, it was not apparent after calcination.

Similar to HPC, EC derivatives have been used as templating agents to construct both inorganic and organic composites. Huang and coworkers synthesized composite materials of ethyl-cyanoethyl cellulose $((\mathrm{E}-\mathrm{CE}) \mathrm{C})$ and polyacrylic acid (PAA) by mixing a solution of (E-CE)C with divinylbenzene, an initiator, and acrylic acid. The mixture was allowed to mature for 2 weeks before photopolymerization and evaporation of the solvent [77-79]. The composite material retained the chiral nematic ordering of the EC derivative and had a reflectance wavelength that was responsive to swelling. In 2010, Huang and coworkers also synthesized $((\mathrm{E}-\mathrm{CE}) \mathrm{C}) /$ silica composites using a similar procedure for the $((\mathrm{E}-\mathrm{CE}) \mathrm{C}) / \mathrm{PAA}$ composite materials (Fig. 4a) [80]. The composite materials showed long-range chiral nematic structure as observed by SEM (Fig. 4b,c). The (E-CE)C/silica composite materials were calcined under air at $550{ }^{\circ} \mathrm{C}$, producing porous silica with BET surface areas of $330-837 \mathrm{~m}^{2} \mathrm{~g}^{-1}$ and pore sizes of $4.8-9.5 \mathrm{~nm}$. Although the resulting silica materials did not retain the chiral nematic structure, the hierarchical structure was dependent on the silica precursor content in the composite.

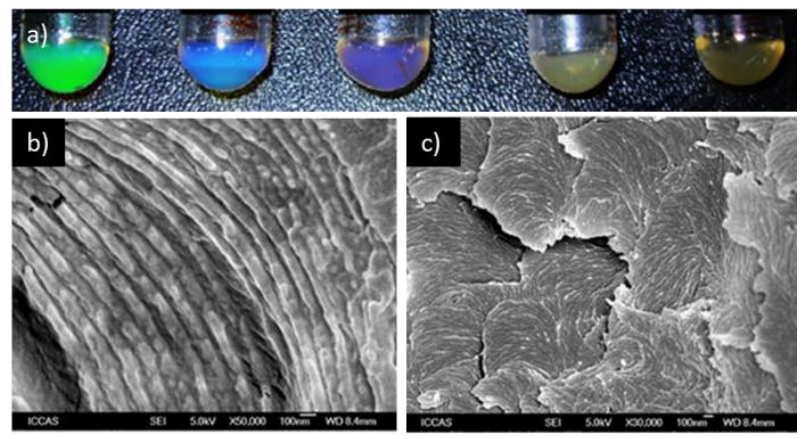

Fig. 4. Templating with ethylcellulose (EC). (a) Photographs (top) of the (E-CE)C/3-(Trimethoxysilyl)propyl methacrylate (MPTOS) cholesteric LC solutions $(b, c)$ SEM micrographs of the freeze-fractured surface of the (ECE)C/poly(MPTOS) composite. Reproduced and adapted from [80] with permission from Springer.

\section{Chitin}




\subsection{Nanocrystalline chitin}

Chitin is the second most abundant naturally occurring polysaccharide, after cellulose, and shares many similarities to cellulose with respect to its physico-chemical properties. However, while cellulose is a major structural component in plants, chitin is largely found in the exoskeleton of beetles and crustaceans as well as in the cell walls of some fungi [81]. Chitin is commercially available and is typically produced by removing proteins and carbonate salts from seafood waste such as shrimp shells. Using acid hydrolysis, the amorphous regions in the chitin microfibrils are removed to give nanocrystalline chitin $(\mathrm{NCh})$, very similar to the process for producing $\mathrm{CNCs}$. Dimensions and properties of NCh depend on the source of chitin and the chemical treatment with the length ranging from $5 \mathrm{~nm}$ to a few micrometers and a diameter from 4 to ca. $70 \mathrm{~nm}[28,82]$. Although colloidal suspensions of chitin and NCh form LC phases [83], they have received much less attention than CNCs for templating, and only a few reports have made use of the chiral nematic phase. Much of the work on chitin templating has been inspired by the fascinating biomineralization of nacre, a biomaterial with remarkable physical properties [84]. Although not all of the examples to be discussed below are based on true LC templating, these approaches illustrate the challenges that arise when using biomolecules as template.

In 2008, Kato and co-workers used carbamated chitin to prepare a nematic gel by soaking the LC solution (15 wt\%) in methanol followed by manual stretching to further align the chitin backbone [85]. The gels were dried and used as a template for the growth of $\mathrm{CaCO}_{3}$. Rod-like $\mathrm{CaCO}_{3}$ crystals aligned along the long axis of the chitin backbone were observed in the stretched gel but were not found when unstretched gels were used, suggesting that the inherent LC order plays a minor role in the growth of the crystals. Recognizing the importance of the ordered structure for directed crystal growth, the group investigated using the LC phase of NCh for templating [86]. Gelation of the chiral nematic phase of chitin was induced by exposing an aqueous chitin suspension to ammonium carbonate vapor. The gel was then placed in $\mathrm{CaCl}_{2}$ and re-exposed to the vapor, resulting in the mineralization of the gel with $\mathrm{CaCO}_{3}$ (Fig. 5a). SEM images of the product, however, showed the composite material had layers but no chiral nematic structure, and no attempts to remove the template were made (Fig. 5b). A breakthrough was achieved by 
adding a small amount of acrylic acid (2 wt \%) to the NCh suspension in order to lock the chiral nematic structure in place by photopolymerization [87]. Incorporation of $\mathrm{CaCO}_{3}$ was then achieved by immersing the sample in a colloidal suspension of amorphous $\mathrm{CaCO}_{3}$, similar to the biomineralization of nacre. Transparent films were obtained, with the weight fraction of $\mathrm{CaCO}_{3}$ of $12 \mathrm{wt} \%$ after $1 \mathrm{~d}$ of deposition time to $23 \mathrm{wt} \%$ after $7 \mathrm{~d}$. In all cases, SEM proved the chiral nematic order of the composite material and EDX showed homogeneous distribution of $\mathrm{CaCO}_{3}$ throughout the film (Fig. 5c,d). No attempts to remove the chitin template were reported.
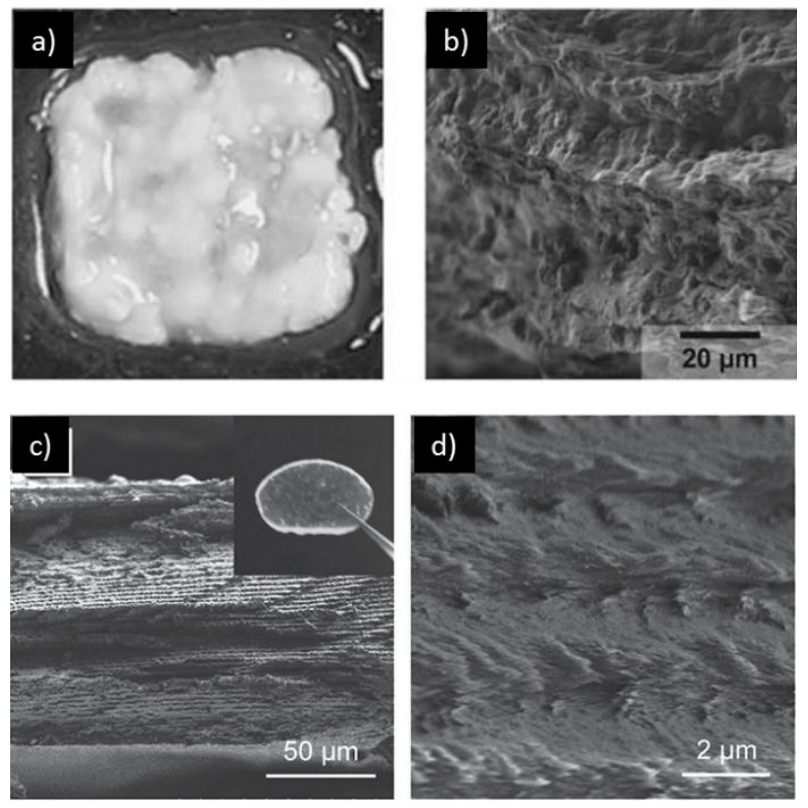

Fig. 5. Chitin $/ \mathrm{CaCO}_{3}$ composite materials. (a) Photograph and (b) SEM image of mineralized chitin gel. Reprinted by permission from Macmillan Publishers Ltd: Polymer Journal [86], copyright 2010. (c,d) SEM image of Poly(acrylic acid)-stabilized chitin/ $\mathrm{CaCO}_{3}$ composite with chiral nematic structure. Reproduced from [87] with permission from John Wiley and Sons.

Alonso and Belamie studied the incorporation of NCh in a silica matrix [88]. They avoided unwanted precipitation by slowly exchanging the solvent and preparing mixtures with pre-synthesized silica colloids at varying ratios. The resulting suspensions were either cast to obtain hard bulk materials, or spray dried to yield particles. NCh was well-dispersed in both materials, but no indication of LC order in the material was observed. Conversely, a strong magnetic field was able to uniformly align the chitin nanorods during the drying process and calcination produced ordered mesoporous silica materials. Further investigations showed that the porosity was dependent on the initial NCh concentration [89] and chiral 
textures were found when the pore volume fraction was around 0.35 . Boltoeva et al. demonstrated that an alternating current electric field is capable of aligning NCh in a few minutes and they used this to obtain chitin-silica composites [90]. With the same method, mesoporous silica-titania and pure alumina catalysts were templated, but no hierarchical order was reported [91-93].

Nguyen et al. were the first to present mesoporous silica and organosilica materials that replicated the layered order of a nematic chitin template (Fig. 6) [94*]. In contrast to previous reports, the NCh showed a nematic rather than chiral nematic phase. Interestingly, the quality of this LC phase was significantly improved when the chitin was deacetylated prior to acid hydrolysis, which was attributed to a higher surface potential of the NCh. These improved chitin suspensions were subsequently used to study the formation of silica/chitin and organosilica/chitin composites. Both composite materials showed the optical birefringence characteristic of nematic phases, thus providing evidence for preservation of the LC template structure. The chitin template was removed by calcination in air from the silica composite and by sulfuric acid catalyzed hydrolysis from the organosilica composite, yielding mesoporous silica and organosilica materials with surface areas of up to $650 \mathrm{~m}^{2} \mathrm{~g}^{-1}$ and $800 \mathrm{~m}^{2} \mathrm{~g}^{-1}$, respectively. Pore size distributions closely matched the diameter of the chitin template for the samples hydrolyzed in acid ( 9 $14 \mathrm{~nm})$ but smaller pores were obtained for the calcined samples $(4-7 \mathrm{~nm})$. Electron microscopy clearly showed a layered structure for both silica and organosilica replicas and spindle-like features visible in the organosilica material (Fig. 6c,d).
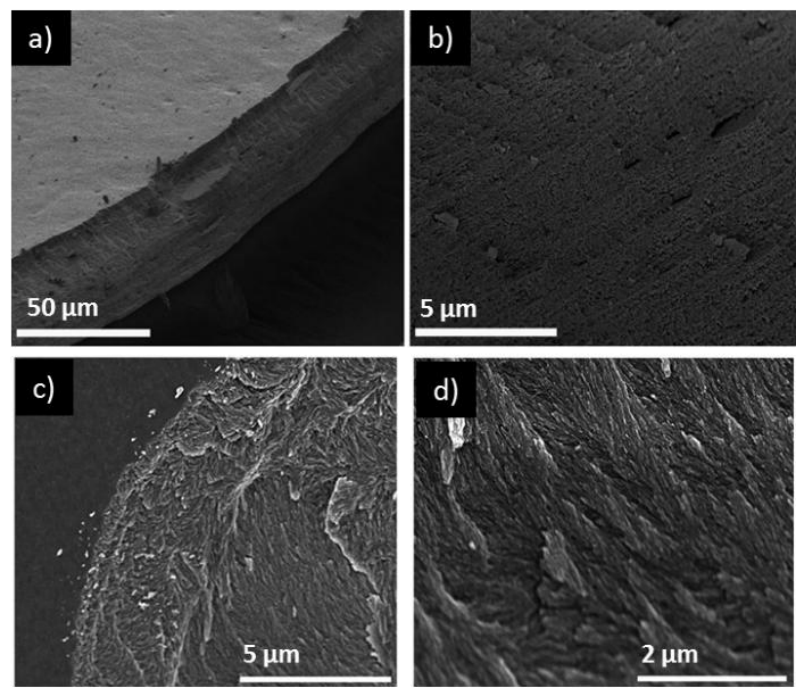
Fig. 6. Mesoporous materials templated from chitin. (a,b) SEM image of templated silica and (c,d) organosilica showing spindle-like features. Reproduced and adapted from [94] with permission from John Wiley and Sons.

The silica/chitin composites were later used to prepare layered nitrogen-doped carbon materials by performing the calcination procedure under nitrogen and etching the silica with sodium hydroxide [95]. Interestingly, the amine groups present in $\mathrm{NCh}$ resulted in a nitrogen-doped (5 wt $\%$ ) carbon material in contrast to chiral mesoporous carbon derived from CNCs. When the chitin content in the original composite was ca. $77 \%$, the carbon materials showed layered structures with aligned pores, reminiscent of the nematic phase, a surface area of $1000 \mathrm{~m}^{2} \mathrm{~g}^{-1}$, and high electrical double layer capacitance, making these materials interesting for use in electrochemical applications.

\subsection{Crab shells}

We would like to finish this section with work that does not use LC templating but is fascinating because it lets nature do the job. Cui and co-workers calcined crab shells under air to remove all organic components and obtained a framework of hollow $\mathrm{CaCO}_{3}$ fibres with a chiral nematic structure (Fig. 7a) [96*]. The hollow channels were uniformly coated with a thin carbon layer, followed by filling the channels with either sulfur or silicon. After removing the $\mathrm{CaCO}_{3}$, nanostructured electrode materials with high specific capacitance and excellent cycling stability were produced (Fig. 7b). Nguyen and MacLachlan carefully separated the cuticle from the inside of a king crab shell and removed all components apart from the chitin matrix [97]. The obtained chitin membrane showed birefringence and selective reflectance of circularly polarized light typical of a chiral nematic structure (Fig. 7c,e). By hydrolyzing TMOS in the pores of the membranes, silica/chitin composites were templated. Subsequent calcination under either air or nitrogen yielded mesoporous silica (Fig. 7d) or nitrogen-doped carbon materials, respectively. Both materials had a well preserved chiral nematic order (shown for silica in Fig. 7f). 

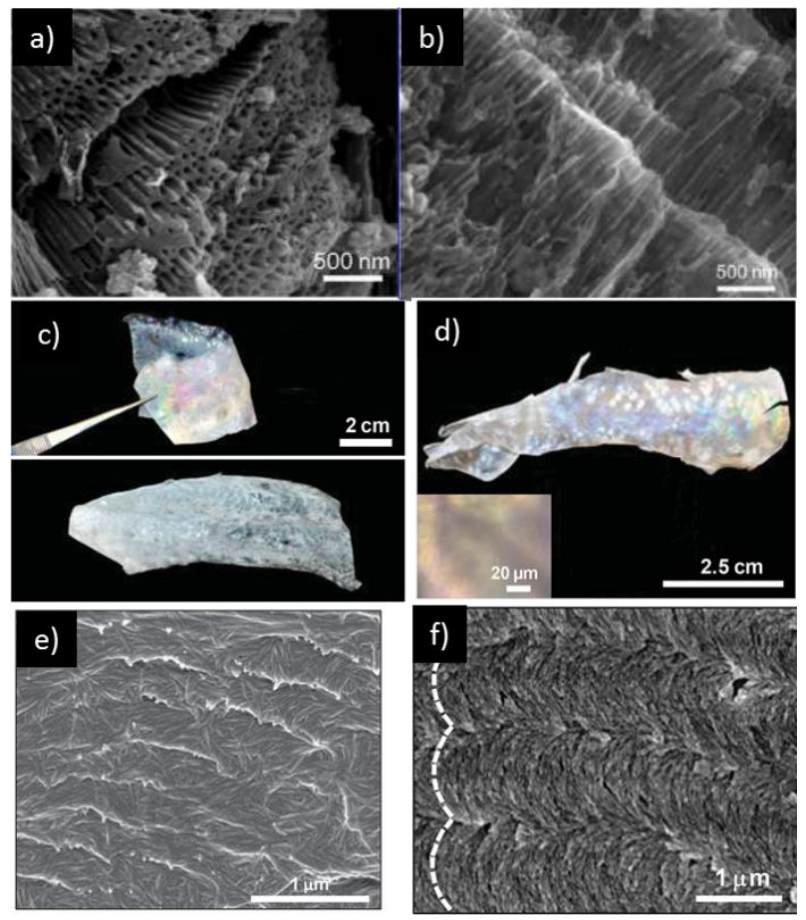

Fig. 7. Mesoporous materials templated from crab shells. (a) SEM images of carbon-coated crab shell template and (b) sulfur encapsulated in carbon nanochannels after etching of the template. Reprinted and adapted with permission from [96], copyright 2013 American Chemical Society. (c) Photograph of wet (top) and dry (bottom) chitin membrane, (d) photograph of corresponding silica replica, (e) SEM image of chitin membrane and (f) SEM image of the corresponding silica replica. Reproduced and adapted from [97] with permission from John Wiley and Sons.

\section{Viruses}

Viruses may be regarded as organic core/shell nanoparticles made from biopolymers [98]. The core of these particles contains the genetic information (DNA or RNA) to replicate the virus and is surrounded by a protective shell of proteins. This so-called capsid typically self-assembles into either helical or icosahedral geometry and presents a versatile handle for materials scientists and chemists through both genetic engineering and chemical modification. Another distinct advantage over synthetic NPs is their monodispersity. Viruses have presented an ideal test system to study ordered phases of hard rod systems at the fundamental level [99*]. However, despite these intriguing properties, templating from LC phases has not yet seen a significant breakthrough.

In 2012, Niu et al. incorporated an assortment of virus nanoparticles (VNPs), including tobacco mosaic virus, turnip yellow mosaic virus and cowpea mosaic virus, in a silica matrix [100]. The VNPs were mixed with a pre-formed silica sol, cast onto glass slides and calcined to yield mesoporous silica. 
Although the morphology of the individual VNPs was well replicated, no long-range order was observed. Retention of the LC ordering from VPNs was first achieved by Mann and co-workers using tobacco mosaic virus (TMV) in 2001 [101*]. APTES and TEOS were co-condensed with the nematic phase of this helical rod-shaped VNP, then the dried gels were calcined to remove the template. TEM images showed micrometer-long silica fragments containing hexagonal periodic arrays of linear channels $11 \mathrm{~nm}$ in diameter and with a periodicity of $20 \mathrm{~nm}$. The formation of these channels was attributed to an end-to-end assembly of TMV in the gel (Fig. 8a). In contrast, low silica to TMV ratios gave silica NPs of 100 to $150 \mathrm{~nm}$ in diameter with channels aligned in a radial fashion (Fig. 8b). Cao and co-workers demonstrated the use of the filamentous phages $f d$ and a series of genetically modified M13 phages with increasing surface charge density for templating of silica [102]. Both VNPs have a high aspect ratio with a length of ca. $880 \mathrm{~nm}$ and a diameter of ca. $7 \mathrm{~nm}$. Following Mann's work, APTES and pre-hydrolyzed TEOS were used to form the silica matrix, and fibers several micrometers long were collected when $f d$ was used as template. Calcination under air successfully removed the template and yielded mesoporous silica materials with ordered channels. Electron microscopy showed clear morphological differences when the M13 derivatives with increasing surface charge density were used (E8-M13 > M13 > R4-M13) as a template, resulting in silica fibers of $2-3 \mu \mathrm{m}, 10-15 \mu \mathrm{m}$, and $1 \mu \mathrm{m}$ length, respectively. The influence of the surface charge density and the interaction between the viruses and APTES was also evident in the resulting pore structures. For the least charged species R4-M13, only one virus per fiber was found because no further aggregation between VNPs occurred. On the other hand, a nematic structure was found for wild type M13 and a smectic structure for E8-M13. This work presents a convincing example of how the surface properties of bacteriophages can be tuned to produce templated silica materials with different morphologies. The use of M13 as a biotemplate for novel materials was extended by incorporating metal nanoparticles within the silica network in a one-pot synthesis [103]. For this purpose, an amine-bearing coat protein and a bioconjugation strategy were employed to anchor thiolated molecules with different length on the surface of the VNP. Remarkably, neither the newly introduced thiol groups nor the addition of gold or platinum ions affected the formation of the ordered virus phase or the condensation of the silica 
framework. When an unfunctionalized control phage was used, polydisperse gold nanoparticles formed on the outside of the resulting silica materials. In contrast, thiol-functionalized phages promoted the homogeneous growth of gold nanoparticles with a diameter of ca. $5 \mathrm{~nm}$ in the silica matrix. It was noted that no additional reducing agent was necessary due to the ability of amine groups present in the coat proteins. In contrast to many other metal-loaded mesoporous materials, the gold NPs were found in the silica walls, leaving the channels accessible. Similar results were found when platinum ions were incorporated during the synthesis, resulting in platinum NPs. Finally, the authors presented the application of the gold-decorated silicas for catalysis. Gold NPs present in the materials obtained from thiolated phages reduced 4-nitrophenol and methylene blue in the presence of sodium borohydride better than those obtained from unmodified M13. This finding was attributed to the particles being homogeneously embedded in the silica walls when thiolated phages were employed as templates.

\section{Collagen}

Fibrous proteins, such as collagen, keratin, elastin and silk, can be found throughout the animal kingdom. These proteins are typically composed of large hydrophobic regions and tend to form rod or wire-like morphologies in in-vivo aqueous environments. The well-defined anisotropic ordering of fibrous proteins makes them promising biotemplates for generating nanostructured materials. Collagen and silk are the most researched of the fibrous proteins but only Type I collagen has been investigated in templating using its liquid crystalline properties.

In humans, twenty-eight different types of collagen comprise one third of the total proteins [104]. Type I collagen is a major structural protein found in modern vertebrates and provides the threedimensional matrix for connective tissues like bone and cartilage. In vivo, collagen has a hierarchical structure resulting from the self-assembly of individual collagen monomers $(\sim 2 \mathrm{~nm}$ in diameter and 300 $\mathrm{nm}$ long) into macromolecular fibers with diameters of >100 nm [104,105]. Cholesteric twists between these larger macromolecular fibrils have been observed in biological tissues like bone. In 1992, GiraudGuille observed a birefringent pattern in an acidic solution of collagen monomers when the dilute collagen 
solution reached a concentration $>100 \mathrm{mg} \mathrm{mL}^{-1}$ due to the formation of a chiral nematic phase $[106,107]$. In vitro, the LC phase obtained was due to twisting of individual triple helices. Fibrils were obtained by exposing the acidic solutions to ammonia, thereby raising the $\mathrm{pH}$ without diluting the sample, causing the collagen monomers to aggregate. This aggregation corresponds to a sol-gel transition and the fibers strongly mimic the organization of collagen in connective tissue.

Most research into templating uses the fibril characteristics of the collagen to create either mesoporous composite materials, fibrous structures, hydrogels or xerogels, but does not utilize the hierarchical LC assembly of collagen. In 2005, Coradin et al. synthesized silica-collagen hybrid materials using collagen as a LC template to produce silica materials that show long-range chiral ordering over several millimeters [108]. A solution of collagen $\left(\sim 100 \mathrm{mg} \mathrm{mL}^{-1}\right)$ in acetic acid formed chiral nematic LC structures of the collagen fibers. Increasing the $\mathrm{pH}$ induced the monomers to self-assemble into a fibrous gel. Silica was then infiltrated into the gel matrix by exposure to TMOS vapors in a closed system for six days. The resulting silica/collagen hybrid materials showed birefringence by POM, and TEM indicated that the long-range LC structure of collagen was retained (Fig. 8c). The collagen template was removed by calcination at $600{ }^{\circ} \mathrm{C}$ or hydrolysis in $1 \mathrm{M} \mathrm{HCl}$ to produce mesoporous silica materials with an average pore size of $2.2 \mathrm{~nm}$, which is slightly larger than the diameter of collagen fibers. TEM and SEM images of the calcined silica showed a continuous but faint microstructure orientation and a unique oriented fiberlike morphology. 

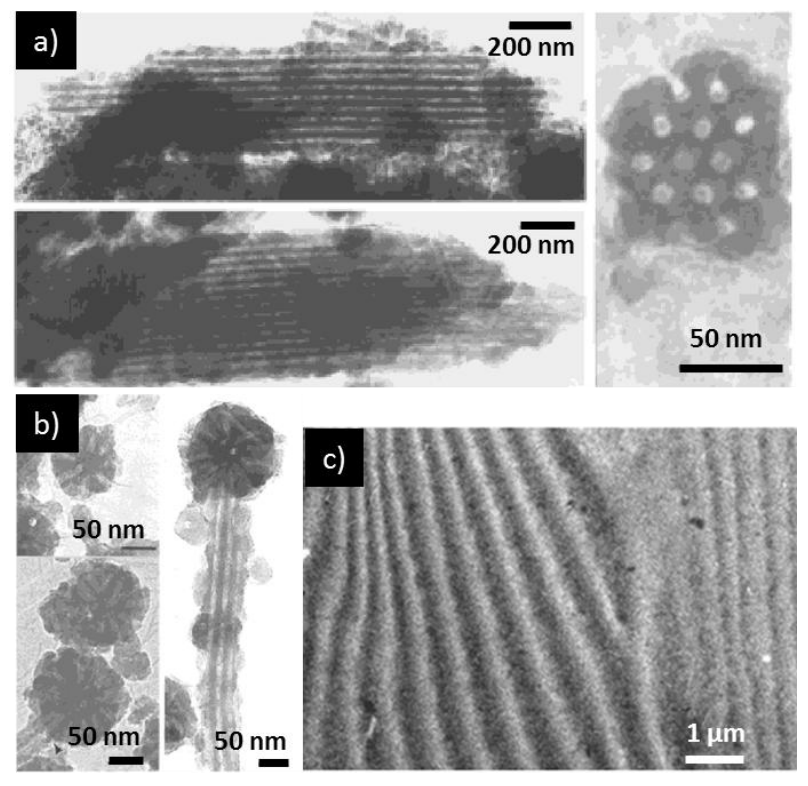

Fig. 8. Templating with TMV and collagen. (a) Hexagonal periodic and (b) radially aligned channels imprinted in silica using TMV. Reproduced and adapted from [101] with permission from John Wiley and Sons. (c) TEM micrographs of silica-concentrated collagen solution hybrid. Reproduced and adapted from [108] with permission from the Royal Society of Chemistry.

\section{Conclusion}

In this perspective, we have shown the emerging world of liquid crystalline biomolecular templating. Using biomolecules as templates is a creative way to capture the structure and organization of nature in a solid-state matrix. After removal of the template, one can obtain porous materials where the pore sizes, shape, and organization are dictated by the choice of liquid crystalline biomolecule employed. These designer porous materials that blend synthetic chemistry with nature's toolbox are promising for applications ranging from molecular storage and separation to photonic sensing.

Cellulose nanocrystals (CNCs) have emerged as a leader in the field owing to their accessibility and reproducible formation of a chiral nematic liquid crystal. Using CNCs as a template, it has proven possible to template a variety of polymeric and inorganic materials, and to indirectly transfer the structure of the biomolecular assembly to new materials through hard templating. These templating strategies with CNCs show promise for developing new materials for sensing, reflective coatings, photonics, decoration, catalysis, and chiral separation. Challenges that remain include controlling the size and monodispersity of the $\mathrm{CNC}$ rods during synthesis and their functionalization to obtain new liquid crystalline materials. 
Simultaneously, there are many other biomolecules that are known to form liquid crystalline phases and show promise as templates for constructing new materials. Using liquid crystal templating of the Bouligand structure of chitin is a good way to incorporate many of the features of liquid crystal templating, but it misses many of the opportunities of using chitin nanocrystals directly. Key to the development of nanocrystalline chitin as a template will be controlling the functionalization and solubility of the chitin while maintaining its liquid crystalline organization.

Many other biomolecules are at a very early stage in terms of liquid crystalline templating collagen and viruses, for example - while there are many other biomolecules that have not been explored as liquid crystalline templates. DNA, RNA, and proteins are promising scaffolds for liquid crystal templating. As chemists have excellent control of their sequences and chain lengths, it is likely that researchers will gain excellent control over their properties and, consequently, the properties of their liquid crystals. Well-defined biomolecules with liquid crystalline phases are promising candidates for forming porous structures with very narrow polydispersity through templating. As well, they offer the opportunity to introduce chirality to materials over multiple length scales.

Considering the rapid growth in this field, we anticipate that many exciting scientific developments and applications will emerge that take advantage of the liquid crystalline properties of biomolecules. Particularly in the field of $\mathrm{CNC}$ research, we look forward to watching new developments appear in the next decade as this field matures! 


\section{Acknowledgements}

This work was supported by the Natural Sciences and Engineering Research Council of Canada (Discovery Grant and scholarship to AST) and the Swiss National Science Foundation (scholarship to GRM, P2ZHP2_155160). We thank our co-workers and collaborators who contributed to the success of the work highlighted here; their names are in the list of references. We thank Thanh Nguyen for acquiring the TEM image of CNCs.

\section{Graphical Abstract}

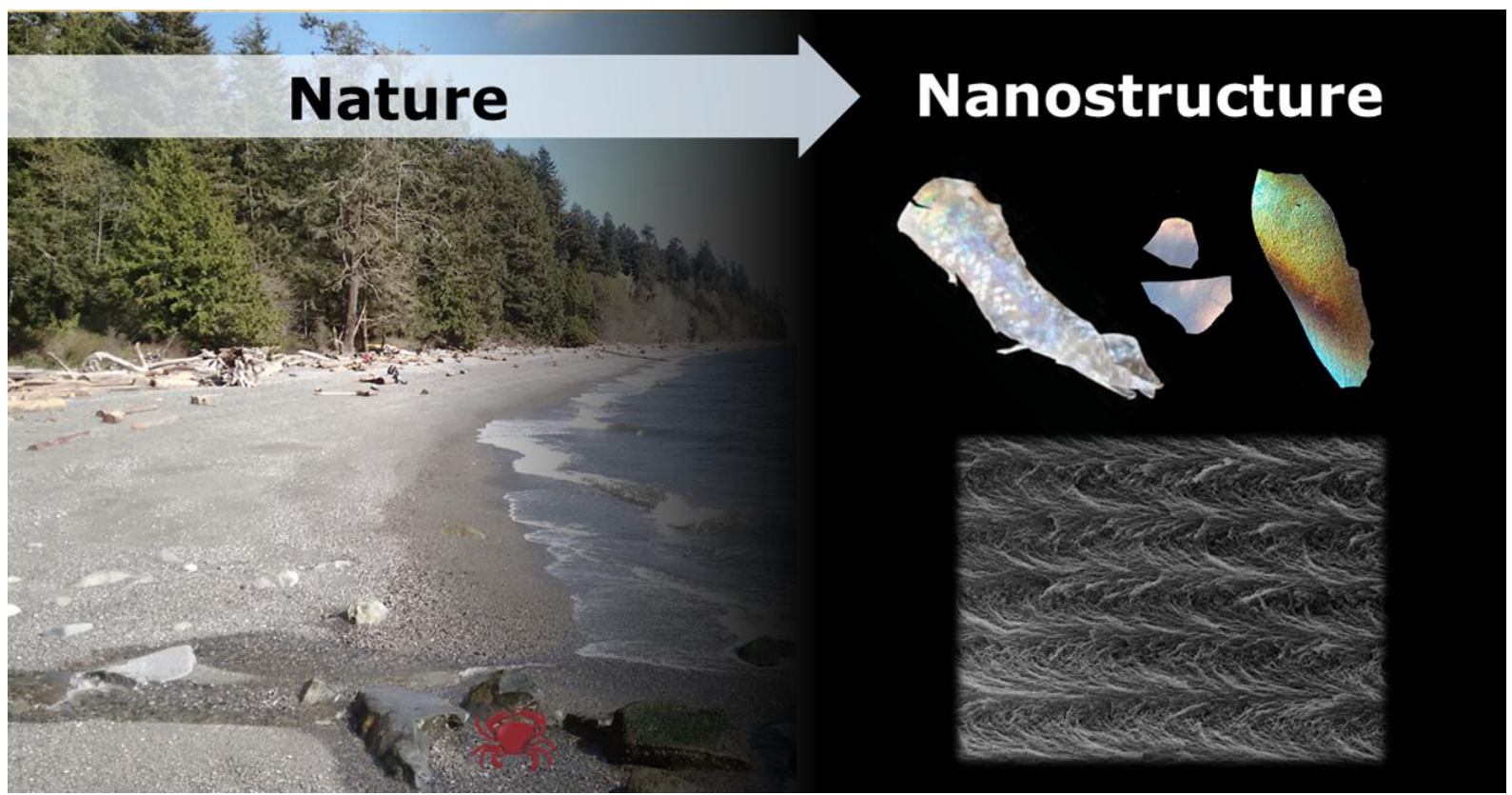


[1] Forster S, Olveira S, Seeger S. Nanotechnology in the market: promises and realities. Int J Nanotechnol 2011;8:592-613.

[2] Lupan O, Ursaki VV, Chai G, Chow L, Emelchenko GA, Tiginyanu IM, et al. Selective hydrogen gas nanosensor using individual $\mathrm{ZnO}$ nanowire with fast response at room temperature. Sens Actuators B Chem 2010;144:56-66. doi:10.1016/j.snb.2009.10.038.

[3] Wang X, Summers CJ, Wang ZL. Large-scale hexagonal-patterned growth of aligned ZnO nanorods for nano-optoelectronics and nanosensor arrays. Nano Lett 2004;4:423-6.

[4] Mor GK, Shankar K, Paulose M, Varghese OK, Grimes CA. Use of Highly-Ordered $\mathrm{TiO}_{2}$ Nanotube Arrays in Dye-Sensitized Solar Cells. Nano Lett 2006;6:215-8. doi:10.1021/nI052099j.

[5] Wang X, Zhi L, Müllen K. Transparent, Conductive Graphene Electrodes for Dye-Sensitized Solar Cells. Nano Lett 2008;8:323-7. doi:10.1021/nl072838r.

[6] Jang E, Jun S, Jang H, Lim J, Kim B, Kim Y. White-Light-Emitting Diodes with Quantum Dot Color Converters for Display Backlights. Adv Mater 2010;22:3076-80. doi:10.1002/adma.201000525.

[7] Kim T-H, Cho K-S, Lee EK, Lee SJ, Chae J, Kim JW, et al. Full-colour quantum dot displays fabricated by transfer printing. Nat Photonics 2011;5:176-82. doi:10.1038/nphoton.2011.12.

[8] Zhou W, Cheng C, Liu J, Tay YY, Jiang J, Jia X, et al. Epitaxial Growth of Branched $\alpha-\mathrm{Fe}_{2} \mathrm{O}_{3} / \mathrm{SnO}_{2}$ Nano-Heterostructures with Improved Lithium-Ion Battery Performance. Adv Funct Mater 2011;21:2439-45. doi:10.1002/adfm.201100088.

[9] Taberna PL, Mitra S, Poizot P, Simon P, Tarascon J-M. High rate capabilities $\mathrm{Fe}_{3} \mathrm{O}_{4}$-based Cu nanoarchitectured electrodes for lithium-ion battery applications. Nat Mater 2006;5:567-73. doi:10.1038/nmat1672.

[10] Kucinskis G, Bajars G, Kleperis J. Graphene in lithium ion battery cathode materials: A review. J Power Sources 2013;240:66-79. doi:10.1016/j.jpowsour.2013.03.160.

[11] Teo BK, Sun XH. From Top-Down to Bottom-Up to Hybrid Nanotechnologies: Road to Nanodevices. J Clust Sci 2006;17:529-40. doi:10.1007/s10876-006-0086-5.

[12] Liu Q, Tang Z, Ou B, Liu L, Zhou Z, Shen S, et al. Design, preparation, and application of ordered porous polymer materials. Mater Chem Phys 2014;144:213-25.

doi:10.1016/j.matchemphys.2014.01.013.

[13] Czaja AU, Trukhan N, Muller U. Industrial applications of metal-organic frameworks. Chem Soc Rev 2009;38:1284-93.

[14] Morris RE, Wheatley PS. Gas Storage in Nanoporous Materials. Angew Chem Int Ed 2008;47:496681. doi:10.1002/anie.200703934.

[15] Perego C, Millini R. Porous materials in catalysis: challenges for mesoporous materials. Chem Soc Rev 2013;42:3956-76. doi:10.1039/C2CS35244C.

[16] Corma A. From Microporous to Mesoporous Molecular Sieve Materials and Their Use in Catalysis. Chem Rev 1997;97:2373-420. doi: 10.1021/cr960406n.

[17] Kresge CT, Leonowicz ME, Roth WJ, Vartuli JC, Beck JS. Ordered mesoporous molecular sieves synthesized by a liquid-crystal template mechanism. Nature 1992;359:710-2. doi:10.1038/359710a0.

[18] Beck JS, Vartuli JC, Roth WJ, Leonowicz ME, Kresge CT, Schmitt KD, et al. A new family of mesoporous molecular sieves prepared with liquid crystal templates. J Am Chem Soc 1992;114:10834-43. doi:10.1021/ja00053a020.

[19] Chen C-Y, Burkett SL, Li H-X, Davis ME. Studies on mesoporous materials II. Synthesis mechanism of MCM-41. Microporous Mater 1993;2:27-34. doi:10.1016/0927-6513(93)80059-4.

[20] Che S, Liu Z, Ohsuna T, Sakamoto K, Terasaki O, Tatsumi T. Synthesis and characterization of chiral mesoporous silica. Nature 2004;429:281-4. doi:10.1038/nature02529.

[21] Kleitz F, Choi SH, Ryoo R. Cubic la3d large mesoporous silica: synthesis and replication to platinum nanowires, carbon nanorods and carbon nanotubes. Chem Commun 2003:2136-7. doi:10.1039/B306504A. 
[22] Zhao D, Huo Q, Feng J, Chmelka BF, Stucky GD. Nonionic Triblock and Star Diblock Copolymer and Oligomeric Surfactant Syntheses of Highly Ordered, Hydrothermally Stable, Mesoporous Silica Structures. J Am Chem Soc 1998;120:6024-36. doi:10.1021/ja974025i.

[23] Sanchez C, Arribart H, Giraud Guille MM. Biomimetism and bioinspiration as tools for the design of innovative materials and systems. Nat Mater 2005;4:277-88. doi:10.1038/nmat1339.

[24] Wysokowski M, Materna K, Walter J, Petrenko I, Stelling AL, Bazhenov VV, et al. Solvothermal synthesis of hydrophobic chitin-polyhedral oligomeric silsesquioxane (POSS) nanocomposites. Int J Biol Macromol 2015;78:224-9. doi:10.1016/j.ijbiomac.2015.04.014.

[25] Hamley IW. Liquid crystal phase formation by biopolymers. Soft Matter 2010;6:1863-71. doi:10.1039/B923942A.

[26] Werbowyj RS, Gray DG. Liquid Crystalline Structure In Aqueous Hydroxypropyl Cellulose Solutions. Mol Cryst Liq Cryst 1976;34:97-103. doi:10.1080/15421407608083894.

[27] Lagerwall JPF, Schütz C, Salajkova M, Noh J, Hyun Park J, Scalia G, et al. Cellulose nanocrystalbased materials: from liquid crystal self-assembly and glass formation to multifunctional thin films. NPG Asia Mater 2014;6:e80. doi:10.1038/am.2013.69.

[28] Li J, Revol J-F, Marchessault RH. Effect of degree of deacetylation of chitin on the properties of chitin crystallites. J Appl Polym Sci 1997;65:373-80. doi:10.1002/(SICI)10974628(19970711)65:2<373::AID-APP18>3.0.CO;2-0.

[29**] Revol J-F, Bradford H, Giasson J, Marchessault RH, Gray DG. Helicoidal self-ordering of cellulose microfibrils in aqueous suspension. Int J Biol Macromol 1992;14:170-2. doi:10.1016/S01418130(05)80008-X. First identification of the chiral nematic phase of CNCs.

[30] Liu B, Cao Y, Huang Z, Duan Y, Che S. Silica Biomineralization via the Self-Assembly of Helical Biomolecules. Adv Mater 2015;27:479-97. doi:10.1002/adma.201401485.

[31] Ross P, Mayer R, Benziman M. Cellulose biosynthesis and function in bacteria. Microbiol Rev 1991;55:35-58.

[32] George J, Sabapathi S. Cellulose nanocrystals: synthesis, functional properties, and applications. Nanotechnol Sci Appl 2015;8:45-54. doi:10.2147/NSA.S64386.

[33] Miao C, Hamad WY. Cellulose reinforced polymer composites and nanocomposites: a critical review. Cellulose 2013;20:2221-62. doi:10.1007/s10570-013-0007-3.

[34] Onofrei MD, Dobos AM, Dunca S, loanid EG, loan S. Biocidal activity of cellulose materials for medical implants. J Appl Polym Sci 2015;132:41932. doi:10.1002/app.41932.

[35**] Shopsowitz KE, Qi H, Hamad WY, MacLachlan MJ. Free-standing mesoporous silica films with tunable chiral nematic structures. Nature 2010;468:422-5. doi:10.1038/nature09540. First report of chiral nematic mesoporous silica templated by CNCs. This was the first definitive transfer of the chiral nematic phase of CNCs to a solid-state material.

[36] Mariano M, El Kissi N, Dufresne A. Cellulose nanocrystals and related nanocomposites: Review of some properties and challenges. J Polym Sci Part B Polym Phys 2014;52:791-806. doi:10.1002/polb.23490.

[37] Šturcová A, His I, Apperley DC, Sugiyama J, Jarvis MC. Structural Details of Crystalline Cellulose from Higher Plants. Biomacromolecules 2004;5:1333-9. doi:10.1021/bm034517p.

[38] Rånby BG. Fibrous macromolecular systems. Cellulose and muscle. The colloidal properties of cellulose micelles. Discuss Faraday Soc 1951;11:158-64. doi:10.1039/DF9511100158.

[39] Marchessault RH, Morehead FF, Walter NM. Liquid Crystal Systems from Fibrillar Polysaccharides. Nature 1959;184:632-3. doi:10.1038/184632a0.

[40] Lagerwall JPF, Scalia G. A new era for liquid crystal research: Applications of liquid crystals in soft matter nano-, bio- and microtechnology. Curr Appl Phys 2012;12:1387-412. doi:10.1016/j.cap.2012.03.019.

[41] Revol JF, Godbout L, Gray DG. Solid self-assembled films of cellulose with chiral nematic order and optically variable properties. J Pulp Pap Sci 1998;24:146-9. 
[42] De Vries H. Rotatory power and other optical properties of certain liquid crystals. Acta Crystallogr 1951;4:219-26. doi:10.1107/S0365110X51000751.

[43] Dujardin E, Blaseby M, Mann S. Synthesis of mesoporous silica by sol-gel mineralisation of cellulose nanorod nematic suspensions. J Mater Chem 2003;13:696-9. doi:10.1039/B212689C.

[44] Brook MA, Chen Y, Guo K, Zhang Z, Brennan JD. Sugar-modified silanes: precursors for silica monoliths. J Mater Chem 2004;14:1469-79. doi:10.1039/B401278J.

[45] Kelly JA, Yu M, Hamad WY, MacLachlan MJ. Large, Crack-Free Freestanding Films with Chiral Nematic Structures. Adv Opt Mater 2013;1:295-9. doi:10.1002/adom.201300015.

[46] Shopsowitz KE, Hamad WY, MacLachlan MJ. Flexible and Iridescent Chiral Nematic Mesoporous Organosilica Films. J Am Chem Soc 2012;134:867-70. doi:10.1021/ja210355v.

[47] Terpstra AS, Shopsowitz KE, Gregory CF, Manning AP, Michal CA, Hamad WY, et al. Helium ion microscopy: a new tool for imaging novel mesoporous silica and organosilica materials. Chem Commun 2013;49:1645-7. doi:10.1039/С3CC38569H.

[48] Shopsowitz KE, Kelly JA, Hamad WY, MacLachlan MJ. Biopolymer Templated Glass with a Twist: Controlling the Chirality, Porosity, and Photonic Properties of Silica with Cellulose Nanocrystals. Adv Funct Mater 2014;24:327-38. doi:10.1002/adfm.201301737.

[49] Nguyen T-D, Hamad WY, MacLachlan MJ. CdS Quantum Dots Encapsulated in Chiral Nematic Mesoporous Silica: New Iridescent and Luminescent Materials. Adv Funct Mater 2014;24:777-83. doi:10.1002/adfm.201302521.

[50] Giese M, De Witt JC, Shopsowitz KE, Manning AP, Dong RY, Michal CA, et al. Thermal Switching of the Reflection in Chiral Nematic Mesoporous Organosilica Films Infiltrated with Liquid Crystals. ACS Appl Mater Interfaces 2013;5:6854-9. doi:10.1021/am402266z.

[51] Giese M, Krappitz T, Dong RY, Michal CA, Hamad WY, Patrick BO, et al. Tuning the photonic properties of chiral nematic mesoporous organosilica with hydrogen-bonded liquid-crystalline assemblies. J Mater Chem C 2015;3:1537-45. doi:10.1039/C4TC02602K.

[52] Zhang J-H, Xie S-M, Zhang M, Zi M, He P-G, Yuan L-M. Novel Inorganic Mesoporous Material with Chiral Nematic Structure Derived from Nanocrystalline Cellulose for High-Resolution Gas Chromatographic Separations. Anal Chem 2014;86:9595-602. doi:10.1021/ac502073g.

[53] Qi H, Shopsowitz KE, Hamad WY, MacLachlan MJ. Chiral nematic assemblies of silver nanoparticles in mesoporous silica thin films. J Am Chem Soc 2011;133:3728-31. doi:10.1021/ja110369d.

[54] Kelly JA, Giese M, Shopsowitz KE, Hamad WY, MacLachlan MJ. The Development of Chiral Nematic Mesoporous Materials. Acc Chem Res 2014;47:1088-96. doi:10.1021/ar400243m.

[55] Shin Y, Exarhos GJ. Template synthesis of porous titania using cellulose nanocrystals. Mater Lett 2007;61:2594-7. doi:10.1016/j.matlet.2006.10.005.

[56] Ivanova A, Fattakhova-Rohlfing D, Kayaalp BE, Rathouský J, Bein T. Tailoring the Morphology of Mesoporous Titania Thin Films through Biotemplating with Nanocrystalline Cellulose. J Am Chem Soc 2014;136:5930-7. doi:10.1021/ja411292u.

[57] Shopsowitz KE, Stahl A, Hamad WY, MacLachlan MJ. Hard Templating of Nanocrystalline Titanium Dioxide with Chiral Nematic Ordering. Angew Chem Int Ed 2012;51:6886-90. doi:10.1002/anie.201201113.

[58] Chu G, Feng J, Wang $\mathrm{Y}$, Zhang $\mathrm{X}, \mathrm{Xu} \mathrm{Y}$, Zhang $\mathrm{H}$. Chiral nematic mesoporous films of $\mathrm{ZrO}_{2}: \mathrm{Eu}^{3+}$ : new luminescent materials. Dalton Trans 2014;43:15321-7. doi:10.1039/C4DT00662C.

[59] Zamarion VM, Khan MK, Schlesinger M, Bsoul A, Walus K, Hamad WY, et al. Photonic metalpolymer resin nanocomposites with chiral nematic order. Chem Commun 2016;52:7810-13 doi:10.1039/C6CC03147A.

[60] Nguyen T-D, Hamad WY, MacLachlan MJ. Hard Photonic Glasses and Corundum Nanostructured Films from Aluminothermic Reduction of Helicoidal Mesoporous Silicas. Chem Mater 2016;28:2581-8. doi:10.1021/acs.chemmater.5b04700. 
[61] Tatsumi M, Teramoto Y, Nishio Y. Polymer Composites Reinforced by Locking-In a LiquidCrystalline Assembly of Cellulose Nanocrystallites. Biomacromolecules 2012;13:1584-91. doi:10.1021/bm300310f.

[62*] Kelly JA, Shukaliak AM, Cheung CCY, Shopsowitz KE, Hamad WY, MacLachlan MJ. Responsive Photonic Hydrogels Based on Nanocrystalline Cellulose. Angew Chem Int Ed 2013;52:8912-6. doi:10.1002/anie.201302687. First report of stimuli-responsive hydrogels templated by CNCs.

[63] Giese M, Khan MK, Hamad WY, MacLachlan MJ. Imprinting of Photonic Patterns with Thermosetting Amino-Formaldehyde-Cellulose Composites. ACS Macro Lett 2013;2:818-21. doi:10.1021/mz4003722.

[64*] Khan MK, Bsoul A, Walus K, Hamad WY, MacLachlan MJ. Photonic Patterns Printed in Chiral Nematic Mesoporous Resins. Angew Chem Int Ed 2015;54:4304-8. doi:10.1002/anie.201410411. Report of ink-jet patterning of chiral nematic mesoporous resins to yield latent images.

[65*] Giese M, Blusch LK, Khan MK, Hamad WY, MacLachlan MJ. Responsive Mesoporous Photonic Cellulose Films by Supramolecular Cotemplating. Angew Chem Int Ed 2014;53:8880-4. doi:10.1002/anie.201402214. First report of a chiral nematic mesoporous cellulose from a supramolecular co-templating method.

[66] Khan MK, Giese M, Yu M, Kelly JA, Hamad WY, MacLachlan MJ. Flexible Mesoporous Photonic Resins with Tunable Chiral Nematic Structures. Angew Chem Int Ed 2013;52:8921-4. doi:10.1002/anie.201303829.

[67] Cheung CCY, Giese M, Kelly JA, Hamad WY, MacLachlan MJ. Iridescent Chiral Nematic Cellulose Nanocrystal/Polymer Composites Assembled in Organic Solvents. ACS Macro Lett 2013;2:101620. doi:10.1021/mz400464d.

[68] Schlesinger M, Hamad WY, MacLachlan MJ. Optically tunable chiral nematic mesoporous cellulose films. Soft Matter 2015;11:4686-94. doi:10.1039/C5SM00745C.

[69] Schlesinger M, Giese M, Blusch LK, Hamad WY, MacLachlan MJ. Chiral nematic cellulose-gold nanoparticle composites from mesoporous photonic cellulose. Chem Commun 2014;51:530-3. doi:10.1039/C4CC07596J.

[70] Shopsowitz KE, Hamad WY, MacLachlan MJ. Chiral Nematic Mesoporous Carbon Derived From Nanocrystalline Cellulose. Angew Chem Int Ed 2011;50:10991-5. doi:10.1002/anie.201105479.

[71] Simon P, Gogotsi Y. Materials for electrochemical capacitors. Nat Mater 2008;7:845-54. doi:10.1038/nmat2297.

[72] Burghard M, Klauk H, Kern K. Carbon-Based Field-Effect Transistors for Nanoelectronics. Adv Mater 2009;21:2586-600. doi:10.1002/adma.200803582.

[73] Ogiwara T, Katsumura A, Sugimura K, Teramoto Y, Nishio Y. Calcium Phosphate Mineralization in Cellulose Derivative/Poly(acrylic acid) Composites Having a Chiral Nematic Mesomorphic Structure. Biomacromolecules 2015;16:3959-69. doi:10.1021/acs.biomac.5b01295.

[74] Chiba R, Nishio Y, Sato Y, Ohtaki M, Miyashita Y. Preparation of Cholesteric (Hydroxypropyl)cellulose/Polymer Networks and Ion-Mediated Control of Their Optical Properties. Biomacromolecules 2006;7:3076-82. doi:10.1021/bm060567t.

[75] Goto H, Akagi K. Optically Active Electrochromism of Poly(3,4-ethylenedioxythiophene) Synthesized by Electrochemical Polymerization in Lyotropic Liquid Crystal of Hydroxypropyl Cellulose/Water: Active Control of Optical Activity. Chem Mater 2006;18:255-62. doi:10.1021/cm050755a

[76] Thomas A, Antonietti M. Silica Nanocasting of Simple Cellulose Derivatives: Towards Chiral Pore Systems with Long-Range Order and Chiral Optical Coatings. Adv Funct Mater 2003;13:763-6. doi:10.1002/adfm.200304383. 
[77] Wang X, Wang L, Huang Y. Effect of swelling on the cholesteric structure of ethyl-cyanoethyl cellulose/crosslinked poly(acrylic acid) composite films. J Appl Polym Sci 2004;91:3574-8. doi:10.1002/app.13585.

[78] Wang L, Wang X, Huang Y. Optical properties of ethyl-cyanoethyl cellulose/poly(acrylic acid) cholesteric liquid crystalline composite films. J Appl Polym Sci 2004;92:213-7. doi:10.1002/app.13433.

[79] Jiang SH, Huang Y, Shen JR. Effects of cholesteric order on mechanical properties of (E-CE)C/PAA composites. J Appl Polym Sci 1995;57:493-8. doi:10.1002/app.1995.070570411.

[80] Wang W, Liu R, Liu W, Tan J, Liu W, Kang H, et al. Hierarchical mesoporous silica prepared from ethyl-cyanoethyl cellulose cholesteric liquid crystalline phase. J Mater Sci 2010;45:5567-73. doi:10.1007/s10853-010-4618-x.

[81] Tharanathan RN, Kittur FS. Chitin - The Undisputed Biomolecule of Great Potential. Crit Rev Food Sci Nutr 2003;43:61-87. doi:10.1080/10408690390826455.

[82] Mincea M, Negrulescu A, Ostafe V. Preparation, modification, and applications of chitin nanowhiskers: a review. Rev Adv Mater Sci 2012;30:225-242.

[83] Belamie E, Davidson P, Giraud-Guille MM. Structure and Chirality of the Nematic Phase in $\alpha$-Chitin Suspensions. J Phys Chem B 2004;108:14991-5000. doi:10.1021/jp048152u.

[84] Cartwright JH., Checa AG. The dynamics of nacre self-assembly. J R Soc Interface 2007;4:491-504. doi:10.1098/rsif.2006.0188.

[85] Nishimura T, Ito T, Yamamoto Y, Yoshio M, Kato T. Macroscopically Ordered Polymer $/ \mathrm{CaCO}_{3}$ Hybrids Prepared by Using a Liquid-Crystalline Template. Angew Chem Int Ed 2008;47:2800-3. doi:10.1002/anie.200705062.

[86] Yamamoto Y, Nishimura T, Saito T, Kato T. $\mathrm{CaCO}_{3} /$ chitin-whisker hybrids: formation of $\mathrm{CaCO}_{3}$ crystals in chitin-based liquid-crystalline suspension. Polym J 2010;42:583-6. doi:10.1038/pj.2010.32.

[87] Matsumura S, Kajiyama S, Nishimura T, Kato T. Formation of Helically Structured Chitin $/ \mathrm{CaCO}_{3}$ Hybrids through an Approach Inspired by the Biomineralization Processes of Crustacean Cuticles. Small 2015;11:5127-33. doi:10.1002/smll.201501083.

[88] Alonso B, Belamie E. Chitin-Silica Nanocomposites by Self-Assembly. Angew Chem Int Ed 2010;49:8201-4. doi:10.1002/anie.201002104.

[89] Belamie E, Boltoeva MY, Yang K, Cacciaguerra T, Alonso B. Tunable hierarchical porosity from selfassembled chitin-silica nano-composites. J Mater Chem 2011;21:16997-7006. doi:10.1039/C1JM12110C.

[90] Boltoeva MY, Dozov I, Davidson P, Antonova K, Cardoso L, Alonso B, et al. Electric-Field Alignment of Chitin Nanorod-Siloxane Oligomer Reactive Suspensions. Langmuir 2013;29:8208-12. doi:10.1021/la401448e.

[91] Sachse A, Hulea V, Kostov KL, Marcotte N, Boltoeva MY, Belamie E, et al. Efficient mesoporous silica-titania catalysts from colloidal self-assembly. Chem Commun 2012;48:10648-50. doi:10.1039/C2CC35127G.

[92] Sachse A, Hulea V, Kostov KL, Belamie E, Alonso B. Improved silica-titania catalysts by chitin biotemplating. Catal Sci Technol 2014;5:415-27. doi:10.1039/C4CY00978A.

[93] Sachse A, Cardoso L, Kostov KL, Gérardin C, Belamie E, Alonso B. Mesoporous Alumina from Colloidal Biotemplating of Al Clusters. Chem - Eur J 2015;21:3206-10. doi:10.1002/chem.201405444.

[94*] Nguyen T-D, Shopsowitz KE, MacLachlan MJ. Mesoporous Silica and Organosilica Films Templated by Nanocrystalline Chitin. Chem - Eur J 2013;19:15148-15154. doi:10.1002/chem.201301929. First report of sacrificial templating of the nematic phase of nanocrystalline chitin.

[95] Nguyen T-D, Shopsowitz KE, MacLachlan MJ. Mesoporous nitrogen-doped carbon from nanocrystalline chitin assemblies. J Mater Chem A 2014;2:5915-21. doi:10.1039/C3TA15255C. 
[96*] Yao H, Zheng G, Li W, McDowell MT, Seh Z, Liu N, et al. Crab Shells as Sustainable Templates from Nature for Nanostructured Battery Electrodes. Nano Lett 2013;13:3385-90.

doi:10.1021/nl401729r. Striking example of using a sustainable resource as template for energy materials.

[97] Nguyen T-D, MacLachlan MJ. Biomimetic Chiral Nematic Mesoporous Materials from Crab Cuticles. Adv Opt Mater 2014;2:1031-7. doi:10.1002/adom.201400279.

[98] Fischlechner M, Donath E. Viruses as Building Blocks for Materials and Devices. Angew Chem Int Ed 2007;46:3184-93. doi:10.1002/anie.200603445.

[99*] Dogic Z, Fraden S. Ordered phases of filamentous viruses. Curr Opin Colloid Interface Sci 2006;11:47-55. doi:10.1016/j.cocis.2005.10.004. Comprehensive review on LC phases formed by viruses that helps to understand the formation of LC phases in particle systems in general.

[100] Niu Z, Kabisatpathy S, He J, Lee LA, Rong J, Yang L, et al. Synthesis and characterization of bionanoparticle-Silica composites and mesoporous silica with large pores. Nano Res 2010;2:47483. doi:10.1007/s12274-009-9043-6.

[101*] Fowler CE, Shenton W, Stubbs G, Mann S. Tobacco Mosaic Virus Liquid Crystals as Templates for the Interior Design of Silica Mesophases and Nanoparticles. Adv Mater 2001;13:1266-9. doi:10.1002/1521-4095(200108)13:16<1266::AID-ADMA1266>3.0.CO;2-9. First example of templating a mesoporous ordered silica from a virus phase.

[102] Mao C, Wang F, Cao B. Controlling Nanostructures of Mesoporous Silica Fibers by Supramolecular Assembly of Genetically Modifiable Bacteriophages. Angew Chem Int Ed 2012;51:6411-5. doi:10.1002/anie.201107824.

[103] Vera-Robles LI, González-Gracida J, Hernández-Gordillo A, Campero A. Using the M13 Phage as a Biotemplate to Create Mesoporous Structures Decorated with Gold and Platinum Nanoparticles. Langmuir 2015;31:9188-97. doi:10.1021/acs.langmuir.5b01741.

[104] Shoulders MD, Raines RT. COLLAGEN STRUCTURE AND STABILITY. Annu Rev Biochem 2009;78:929-58. doi:10.1146/annurev.biochem.77.032207.120833.

[105] Ehrlich H. Chitin and collagen as universal and alternative templates in biomineralization. Int Geol Rev 2010;52:661-99. doi:10.1080/00206811003679521.

[106] Giraud-Guille M-M. Liquid crystallinity in condensed type I collagen solutions. J Mol Biol 1992;224:861-73. doi:10.1016/0022-2836(92)90567-4.

[107] Giraud Guille MM, Mosser G, Helary C, Eglin D. Bone matrix like assemblies of collagen: From liquid crystals to gels and biomimetic materials. Micron 2005;36:602-8. doi:10.1016/j.micron.2005.07.005.

[108] Eglin D, Mosser G, Giraud-Guille M-M, Livage J, Coradin T. Type I collagen, a versatile liquid crystal biological template for silica structuration from nano- to microscopic scales. Soft Matter 2005;1:129-31. doi:10.1039/B503019F. 